The Journal of SPORT, 2020, 8(1), 42-54

(C) Kent State University

\title{
Psychophysiological Measures of Emotional Sport Fan Identification
}

\author{
Brian Yim \\ Kent State University \\ Dean Sabatinelli \\ University of Georgia \\ Laurence McCarthy \\ Seton Hall University \\ Wooyoung Jang \\ Indiana University, Bloomington
}




\begin{abstract}
In today's highly competitive sports business market, sports organizations have shifted their marketing strategy from a traditional exchange to a relationship paradigm. The relationship quality between sports fans and sport organizations contains many emotional constructs, and thus studies of emotion are increasingly relevant in the sports marketing field. While most studies of emotional processing use self-report measures, the objectivity and validity of these metrics are limited by social expectations and demand effects. Psychophysiological measures of emotional processing offer significant potential benefits in the study of sports marketing relationships, including (1) quantitative data through direct measure; (2) the validation and clarification existing in self-report data; and (3) tracking of emotional changes in real time. The utility of psychophysiological measures in the study of team sports identification and other relevant paradigms are outlined, and improvements in sports consumer research are discussed.
\end{abstract}

\title{
Introduction
}

In the consumer behavior field, researchers have traditionally used cognitive process to explain consumer behavior and the decision-making process (e.g., Bettman, 1979; Engel, Kollat, \& Blackwell, 1968; Howard \& Sheth, 1969). However, there is increasing interest in the role of emotion in consumer behavior (e.g., Pham, 1998; Ladhari, Brun, \& Morales, 2008; Mattila \& Ro, 2008). Several studies report that emotions influence consumer satisfaction, judgments, and postpurchase processes such as return intent, word of mouth generation, and overall assessment of the organization that provided the service (Ladhari et al., 2008; Mano \& Oliver, 1993; Mattila \& Ro, 2008; Westbrook \& Oliver, 1991). In addition, scholars such as Pham $(1998 ; 2004)$ and Isen $(2008)$ attest that emotions play a significant role in consumer decision making processes. Therefore, it is now common for scientists and professionals to investigate the role of emotional experience in consumption behaviors.

Considering the dynamic and dramatic nature of sport spectating, we can reasonably assume that emotions play an important role in sports consumption behavior. In fact, many researchers stress the significance of emotions on sports spectating. Roese and Maniar, (1997) suggest that for fans, sport spectating represents "one of the most passionate and intense of human endeavors, utterly dominating affect and cognition for short periods of time" (p.1245). Hirschman and Stern (2001) added that entertainment commerce (e.g., film, music, art, and sport) benefits tremendously from emotions evoked in the consumption and requires much more emotional dispensation and sensory stimulation than cognitive processing. However, there has been a dearth of objective emotion studies conducted on sport consumption behavior. A limited amount of sport 
consumer behavior research has focused on emotion as an outcome variable (e.g., Sloan, 1979; Cialdini et al., 1976; Snyder, Lassegard, \& Ford, 1986; Hirt, Zillman, Erickson, \& Kennedy, 1992; Schwarz, Strack, Kammer, \& Wagner, 1987) and fewer studies have been conducted using emotions as a mediator or a moderator (e.g., Lim, Martin, \& Kwak, 2010; Kang, Bagozzi, \& Oh, 2011).

It is important to note that the consumption behavior of loyal, or highly identified, fans is different to that of other fan groups, and that they have different emotional responses. If different consumption emotions among sports fan subgroups (e.g., highly identified fans vs. low identified fans) and how consumption behavior and decision making processes are affected by emotional differences could be identified, the information may be helpful in the development of marketing strategies. Key elements in successful sports marketing include the retention of highly identified fans and escalation of moderate fans into loyal fans. This is essential in the modern sport business market that is very competitive and nearly saturated (Kim, Trail, \& Ko, 2011). As the costs of operating a sporting event increase (Fulks, 2008; Kim, Trail, Woo, \& Zhang, 2009), many sports organizations cannot afford the considerable expense of bringing new fans to the market. When a market is saturated and highly competitive, in order to survive, an organization has to change its strategy from acquisition of new consumers to retaining loyal customers (Fornell \& Wernerfelt, 1987), and shift from a traditional exchange to a relationship paradigm (Gladden \& Sutton, 2009; Harris \& Ogbonna, 2008; Mullin, Hardy, \& Sutton, 2007). Through the relationship paradigm, sports organizations can reduce costs by focusing on loyal fans (Fornell \& Wernerfelt, 1987) and repairing damaged relationships with disconnected fans (Kim et al., 2011). Relationship marketing is considered a useful and effective strategy for sport organizations, yet there is limited knowledge on how to measure its influence on sport consumer behavior (Kim et al., 2011). Many constructs of relationship quality have been suggested by researchers (De Wulf, Odekerken-Schröder, \& Iacobucci, 2001; Fournier, 1998; Palmatier, Dant, Grewal, \& Evans, 2006), but in sports consumer behavior, five constructs are considered to be most applicable. These include trust, commitment, intimacy, self-connection, and reciprocity (Kim et al., 2011). Relationship satisfaction (De Wulf et al., 2001; Anderson \& Narus, 1991) and love/passion (Fournier, 1998) are variables also associated with relationship quality.

A key to survival in sports marketing is the ability to retain highly identified fans, yet as there is a scarcity of research in this area, it is useful to review emotional responses that highly identified fans report and how these emotions vary across sport consumption contexts. Studies conducted on sport fan emotions have largely used survey questionnaires. One of the limitations of selfreport methods such as survey questionnaires is the level of difficulty assessing 
latent variables. When using self-report measures, researchers must rely on the honesty of respondents, which is known to be undependable. Furthermore, it is nearly impossible to track the rapidly changing emotional responses of sport fans through self-report methods, as few fans would comply with the distraction (i.e., taking the survey during the game). A potential means of addressing this issue is to track minute changes in facial muscle tension of fans during an actual or represented sporting event. Using the Facial Action Coding System (FACS) (Ekman \& Friesen, 1978), a researcher would be able to follow the facial emotions of fans in a moment-to-moment fashion throughout a sporting event.

Despite the objectivity and utility of psychophysiological measures, few studies have used these methods to examine sports consumer behavior. Because of this scarcity, the related areas of video game research is included in this review. There are several reasons why video game research is relevant to sports marketing research; a) there are heavy and light users of video games (similar to highly identified fans and low identified fans), b) both domains include winning and losing contexts, c) intense emotions are expressed, and d) the behaviors are performed repeatedly.

\section{Emotions in Sport Consumer Behavior with Self Report Measures}

Sloan (1979) conducted a pioneering study of spot spectators' behavior that found that watching sport events significantly impacts spectators' pleasant (winning) and unpleasant (losing) emotions. This research employed a 16-item Mood Adjective Checklist to examine fans' reactions to events, in which the emotional component depended on the game outcome, as well as the fans' reactions and behaviors to maintain self-esteem. A study by Cialdini et al. (1976) examined the level of sport spectators' affective reaction (feelings) in response to sport events. This study suggested that there exists the tendency to "bask in reflected glory" (BIRG) where college students are more likely to wear their school's collegiate athletic apparel on the day after a team victory than after a loss; BIRG refers to the tendency of individuals to display their connection with a successful other. More recently, Knobloch-Westerwick, David, Eastin, Tamborini, and Greenwood (2009) found that sports fans were happier (more satisfied) when there was suspense during the game they watched. This finding suggests there could be several emotional changes throughout the course of a game, and that fans are likely to experience and enjoy a range of unpleasant as well as pleasant emotions while spectating. Several sport consumer (spectator) studies have used emotion as a mediator. Lim et al. (2010) investigated the interceding function of emotion on the relationship between sport spectators' personality and their attitude to mixed martial arts. They found emotion (pleasure and arousal) plays a mediation role and has a significant effect in the relationship 


\section{Psychophysiological Measures of Emotional Sport Fan Identification}

between risk taking and attitude. Kang et al. (2011) examined the role of emotion in the decision-making process in sport consumption (participating) behavior. They studied emotions as antecedents of the decision to initiate participation in a private health club and skiing in an indoor ski resort. Findings revealed that emotion mediates the influence of attitudes and self-image congruency on the decision to join both the club and resort.

In sport consumer studies, researchers have used emotion scales from marketing and psychology, but the emotion measures may only be suitable for the contexts for which they were proposed and developed. For example, Lim et al. (2010) used the pleasure, arousal, and dominance measure (PAD; Mehrabian \& Russell, 1974), which attempts to capture the full spectrum of emotions via three independent dimensions. In Kang et al.'s (2011) study, emotions were assessed using 18 item measures suggested by Bagozzi, Baumgartner, and Pieters' (1998) study. Both scales are frequently used in psychology and marketing and are considered valid and reliable measurement scales that are well developed. However, since the scales were not originally developed to measure sport consumers' emotions, there may be a gap between the scale values and a complete assessment of sport fans' reactions. Also, considering the intense emotional expression of sport fans, psychophysiological measures may more accurately gauge fans' emotions without the possibility of biases in self-report.

\section{Psychophysiological Measures of Emotional Sports Identification}

One of the few studies that measured sport fans' emotions with physiological methods is Hillman et al.'s (2000) study on the responses among identified sport fans. According to Lang (1985), emotion is defined as an action disposition that organizes behavior along a biphasic approach-withdrawal dimension. To measure the affective responses, pictures (Lang, Greenwald, Bradley, \& Hamm, 1993), sounds (Bradley, Zack, \& Lang, 1994), images (Vrana \& Lang, 1990), and sentences (Russell \& Mehrabian, 1977) have been used to evoke emotions. Hillman (2000) and colleagues presented 40 undergraduates with 10 color slides that depicted five scenes from two affective categories: 1) teamrelevant sport, and 2) team-irrelevant sport with 50 other slides that depicted other emotional and neutral contents.

The P300 event-related potential (ERP), heart-rate, and startle-blink reflex were measured. Results indicated that during the team-relevant pictures the P300 component of the event-related potential to the acoustic startle probe was decreased, signifying increased attention to the team picture. Heart rate was decelerated during team pictures. Different responses were found across levels of sport fan identification, implying that the pictures evoked motivated attention for highly identified fans. Increased slow-wave cortical positivity was also found for 
team-relevant pictures, but in this measure, there was no sport fan identification level difference. These data reveal that there is a physiological component to sports identification, and that noninvasive psychophysiological methods are capable of tracking emotional responses evoked by sports fan as they view relevant sports images.

Hillman et al.'s (2000) study also found that highly identified fans reported increased arousal and pleasantness ratings for team-relevant compared to team-irrelevant pictures. Similar patterns have been observed in studies regarding team identification, which have uncovered a variety of cognitive, affective, and behavioral outcomes (Boyle \& Magnusson, 2007; Kwon, Trail, \& Anderson, 2005; Trail, Fink, \& Anderson, 2000; Wann \& Grieve, 2005). Team identification stems from social identity theory (Fink, Parker, Brett, \& Higgins, 2009), which suggests that in order to maintain high self-esteem level, one must be a member of social groups (Tajfel \& Turner, 1986). People in groups make social comparisons in an effort to enhance their self-esteem; they have favorable attitudes toward their own group (in-group) and categorize other groups (out-groups) as inferior (Hogg \& Abrams, 1999). This is frequently observed in sports fans. Highly identified fans are more likely to show favoritism toward other fans of their team and criticize fans of opposing teams (Wann \& Branscombe, 1995; Wann \& Grieve, 2005). These highly identified fans see their team as an extension of themselves (Wann, Melnkick, Russell, \& Pease, 2001). In this area of research, in-group and out-group phenomenon were measured via self-report; however, a physiological measure may be particularly valuable for attitudes that participants may be unwilling to report openly.

In-group. In-group is an important concept in sport marketing as it is highly related to team identification, which stems from social identity theory (Tajfel \& Turner, 1986). According to Tajfel and Turner (1986), individuals have both a personal and a social identity, which serves as the essential concept of social identity theory. The personal identity consists of attributes such as abilities and interests, which are distinct to the person. Alternatively, social identity consists of significant social group categories, such as demographic classifications or organizational membership (Turner, 1982). By being in a certain social group, the individual seeks to increase his/her self-esteem (Tajfel \& Turner, 1986), and in order to accomplish this, members compare in-group to out-group and harbor favorable attitudes toward in-group characteristics, while considering the outgroup as inferior (Hogg \& Abrams, 1999).

This in-group bias is readily identified among sports fans. Many studies have found that highly identified fans show favoritism toward in-group members (fans of their own team) and criticize out-group members (fans of opposing teams); (Branscombe \& Wann, 1994; Wann \& Branscombe, 1995; Wann \& Grieve, 2005). Previous findings suggest that highly identified fans, who show in- 
group bias tendency, are less likely to distance themselves from their favorite team than low identified fans in losing situations (Wann \& Branscombe, 1995). Therefore, in-group favoritism could play an important role in predicting sport fans' identification level and the reactive physiology. If in group favoritism could be assessed accurately and objectively through physiological methods sport marketers could better predict sports fans' behavior, as in-group favoritism has a close relationship with sport fans' identification level.

In social neuroscience, Volz, Kessler, and von Cramon (2009) measured in-group favoritism and in-group bias using fMRI. Results suggested that the dorsomedial prefrontal cortex is associated with performing social identity processes, and dmPFC activity is correlated with the degree of in-group bias. Thus, there is growing evidence for a neural basis of sports identification and loyalty that may be of great utility in sports marketing.

Rivalry. Rivalry, which may be considered as out-group bias in an extreme form, is highly relevant to sports marketing. Rivalry can be national, regional, historical, and in every sport segment. A game against a rival generates extra attention because the magnitude of the outcome is amplified which heightens self-esteem, pride, and emotion related to the game. This is especially true in highly identified fans, who display more intense responses to rivals. In sports marketing, appreciating rivalry and fans' emotions regarding rivalry is particularly important, as it has high marketing value. A major issue in measuring emotions of rivalry through self-report is the fact that many sport fans are unlikely to reveal the full extent of their negative emotional responses towards rivals.

To address this issue, Hillman and colleagues (2004) measured psychophysiological responses of rival fans. The researchers presented images of pleasant team-relevant scenes, team-irrelevant sport scenes, team-relevant unpleasant scenes, erotica, household object, and mutilation scenes to 24 participants divided into two groups based on their identification with local teams. Subjective measures (both valence and arousal), as well as the startle-blink reflex, P300 ERP, slow cortical potentials, skin conductance, and orbicularis oculi EMG were recorded. Findings revealed that team relevant pictures, whether winning or losing, triggered stronger physiological responses across all measures than teamirrelevant pictures. Orbicularis oculi EMG showed greater muscle tension when sports fans viewed scenes of their team winning relative to all other sports images. In this study, the consistency of physiological response across sports contents suggests that elevated reactivity is a hallmark of sports spectating and that viewing competing teams is as activating as viewing one's own team. This information would be difficult to uncover using self-report measures.

Emotions during a game. Ruiz-Belda, Fernandez-Dols, Carrera, and Barchard (2003) attempted to capture sport fans' emotions while spectating a game by analyzing spontaneous facial expressions with the Facial Action Coding 
System (FACS; Ekman \& Friesen, 1978). The researchers covertly tracked, via video playback, a group of 20 Spanish soccer fans' facial musculature while they were watching important matches on television. FACS measures facial movements according to specific Action Units (AU) and captures essentially all of the movements of facial muscles (Ruiz-Belda et al., 2003). The researchers also asked participants to rate their happiness and found (among those who reported happiness watching the game) that there is a low probability of smiling when there was no social interaction (.07) and a high probability of smiling during social interaction (.70). Their findings refuted the idea that smiles are an independent indicator of pleasant emotion and suggested that there is a complex relationship between smiles, pleasure, and sociality during sporting events. Again, these responses would be impossible to measure with self-reported data.

Rajava, Saari, Salminen, Laarni, and Kallinene (2006) investigated video gamers' psychophysiological responses to different emotional events, including positive (winning) and negative (losing) situations . Researchers measured facial EMG (zygomaticus major, corrugator supercilii, and orbicularis oculi), skin conductance level (SCL), and heart rate (HR) while 36 adults played a competitive video game. The researchers categorized eight game events representing positive, negative, and neutral outcomes. Results indicated that during positive events, participants showed increased HR, increased SCL, and an increase of zygomaticus major and orbicularis oculi EMG tension, consistent with a state of positive emotion (Lang, 1985). During negative events, participants showed HR deceleration, SCL increase, and zygomatic and orbicularis oculi EMG activity decrease, suggesting a negative affect state. Importantly, these positive and negative events often occurred in rapid succession, and the physiological measures effectively tracked these dynamic transitions.

\section{Discussion}

While exercise science adopted psychophysiological methods long ago, the sports consumption field (sports fans and sport spectating) has only begun to take advantage of the utility of these techniques. A potential reason why psychophysiological measures are not more commonly used in sport consumption science is that most (but not all) measures are sensitive to physiological arousal, rather than pleasure. However, it may be that arousal is more relevant to fans enjoyment of sports than pleasant affect, as is the case with close games between well-matched opponents. Therefore, the sensitivity of physiological measures of arousal could be a considerable advantage over self-report measures.

Unlike emotion neuroscience, scholars in sport consumer behavior are interested in emotions as a means to an end; to enable the accurate assessment of decision-making processes and future behavioral intentions. Therefore, sport 


\section{Psychophysiological Measures of Emotional Sport Fan Identification}

consumption emotional reactivity will necessitate parametric study in established paradigms to enable the emotional status of sport consumers to be understood. Thought the potential payoff is great, the application of psychophysiological measures will require a considerable investment of time and resources by researchers.

In conclusion, we suggest psychophysiological measures as a powerful option to sports marketing researchers investigating areas that are susceptible to the inherent biases and limitations of survey questionnaires. The advantages and benefits of psychophysiological measures in sport consumer research include; 1) objectivity of measures that are beyond voluntary control, and, thus, safe from demand effects; 2) converging support or contradictory evidence for models based on self-report measures, and 3) the ability to track rapidly changing emotional reactivity in sports fans without the need to interrupt and question thus preserving the ecological validity of the measure. Psychophysiological measures can bring a wealth of information to sports consumption sciences. By integrating the two methods in any single study, researchers will be able to increase validity and greatly extend the efficiency of their research.

\section{References}

Anderson, J. C, \& Narus, J. A. (1991). Partnering as a focused market strategy. California Management Review, 33(3), 95-113.

Bagozzi, P. R., Baumgartner, H., \& Pieters, R. (1998). Goal directed emotions. Cognition and Emotion, 12, 1-26.

Bettman, J. R. (1979). An information processing theory of consumer choice. Reading, MA: Addison-Wesley.

Boyle, B. A., \& Magnusson, P. (2007). Social identity and brand equity formation: a comparative study of collegiate sports fans. Journal of Sport Management, 21(4), 497-520.

Bradley, M.M., Zack, J., \& Lang, P.J. (1994) Cries, screams, and shouts of joy: Affective responses to environmental sounds. Psychophysiology, 31, S29.

Branscombe, N. R., \& Wann, D. L. (1994). Collective self-esteem consequences of outgroup derogation when a valued social identity is on trial. European Journal of Social Psychology, 24, 641-657.

Cialdini, R. B., Borden, R. J., Thorne, A., Walker, M. R., Freeman, S., \& Sloan, L. R. (1976). Basking in reflected glory: Three (football) field studies. Journal of Personality and Social Psychology, 34, 366-375.

De Wulf, K., Odekerken-Schröder, \& Iacobucci, D. (2001). Investments in consumer relationships: A cross-country and cross-industry exploration. Journal of Marketing, 61(4), 35-51. 
Ekman, P., \& Friesen, W. V. (1978). Facial action coding system (FACS): Investigator's guide (Part Two). Palo Alto, CA: Consulting Psychologists Press.

Engel, J. F., Kollat, D. T., \& Blackwell, R. D. (1968). Consumer behaviour. New York: Holt, Rinehart and Winston.

Fink, J. S., Parker, H. M., Brett, M., \& Higgins, J. (2009). Off-field behavior of athletes and team identification: Using social identity theory and balance theory to explain fan reactions. Journal of Sport Management, 23(2), 142-155.

Fornell, C, \& Wernerfelt, B. (1987). Defensive marketing strategy by customer complaint management: A theoretical analysis. JMR, Journal of Marketing Research, 24, 337-346.

Fournier, S. M. (1998). Consumers and their brands: Developing relationship theory in consumer research. Journal of Consumer Research. 24, 343373.

Fulks, D.L. (2008). 2004-2006 revenues and expenses of Division I intercollegiate athletics programs report. Indianapolis, IN: National Collegiate Athletic Association.

Gladden, J.M., \& Sutton, W.A. (2009). Marketing principles applied to sport management. In H.P. Masteralexis, CA. Barr, \& M.A. Hums (Eds.), Principles and practices of sport management (pp. 42-59). Sudbury, MA: Jones and Bartlett Publishers.

Harris, L. C., \& Ogbonna, E. (2008). The dynamics underlying service firmcustomer relationships: Insights from a study of English Premier League soccer fans. Journal of Service Research, 10, 382-399.

Hillman, C. H., Cuthbert, B. N., Bradley, M. M., \& Lang, P. J. (2004). Motivated engagement to appetitive and aversive fanship cues:

Psychophysiological responses of rival sport fans. Journal of Sport \& Exercise Psychology, 26(2), 338-351.

Hillman, C. H., Cuthbert, B. N., Cauraugh, J., Schupp, H. T., Bradley, M. M., \& Lang, P. J. (2000). Psychophysiological responses of sport fans.

Motivation \& Emotion, 24(1), 13-28.

Hirschman, E. B., \& Stern, B. B. (2001). Do consumers' genes influence their behavior? Findings on novelty seeking and compulsive consumption. Advances in Consumer Research, 28(1), 403-410.

Hirt, E., Zillman, D., Erickson, G., \& Kennedy, C. (1992). The costs and benefits of allegiance: Changes in fans self-ascribed competencies after team victory versus team defeat. Journal of Personality and Social Psychology, 63, 724-738.

Hogg, M. A., \& Abrams, D. (1999). Social identity and social cognition. London: Blackwell. 


\section{Psychophysiological Measures of Emotional Sport Fan Identification}

Howard, J. A., \& Sheth, J. N. (1969). The theory of buyer behaviour. New York: Wiley.

Isen, A. M. (2008). Positive affect and decision processes: some recent theoretical developments with practical implications. Handbook of consumer psychology. New York : Lawrence Erlbaum Associates.

Kang, J., Bagozzi, R. P., \& Oh, J. (2011). Emotions as antecedents of participant sport consumption decisions: A model integrating emotive, self-based, and utilitarian evaluations. Journal of Sport Management, 25(4), 314325.

Kim, Y. K., Trail, G., \& Ko, Y. J. (2011). The influence of relationship quality on sport consumption behaviors: An empirical examination of the relationship quality framework. Journal of Sport Management.

Kim, Y. K., Trail, G. T., Woo, B., \& Zhang, J. J. (2009). Sport consumer-team relationship quality: Development and psychometric evaluation of a scale. Sport Marketing Association. Paper presented at the annual conference of Sport Marketing Association, Cleveland, Ohio.

Knobloch-Westerwick, S., David, P., Eastin, M., Tamborini, R., \& Greenwood, D. (2009). Sports spectators' suspense: Affect and uncertainty in sports entertainment. Journal of Communication, 59(4), 750-767.

Kwon, H. H., Trail, G. T., \& Anderson, D.S. (2005). Are multiple points of attachment necessary to predict cognitive, affective, conative, or behavioral loyalty? A case analysis. Sport Management Review, 8(3), 255-270.

Ladhari, R., Brun, I., \& Morales, M. (2008). Determinants of dining satisfaction and post-dining behavioral intentions. International Journal of Hospitality Management, 27(4), 563-573.

Lang, P. J. (1985). The cognitive psychophysiology of emotion: Fear and anxiety. In A. Hussain Tuma \& J. Maser (Eds.), Anxiety and the anxiety disorders (pp. 131-170). Hillsdale, NJ: Erlbaum.

Lang, P. J., Greenwald, M. K., Bradely, m. M., \& Hamm, A. O. (1993). Looking at pictures: Affective, facial, visceral, and behavioral reactions. Psychophysiology, 30, 261-273.

Lim, C. H., Martin, T. G., \& Kwak, D. H. (2010). Examining television consumers of mixed martial arts: The relationship among risk taking, emotion, attitude, and actual sport-media-consumption behavior. International Journal of Sport Communication, 3(1), 49-63.

Mano, H., \& Oliver, R. L. (1993). Assessing the dimensionality and structure of the consumption experience: Evaluation, feeling, and satisfaction. Journal of Consumer Research, 20(3), 451-466. 
Mattila, A. S., \& Ro, H. (2008). Discrete negative emotions and customer dissatisfaction responses in a casual restaurant setting. Journal of Hospitality and Tourism Research, 32(1), 89-107.

Mehrabian, A., \& Russell, J. A. (1974). An approach to environmental psychology. Cambridge, MA: MIT Press.

Mullin, B.J., Hardy, S., \& Sutton, W.A. (2007). Sport marketing. Champaign, IL: Human Kinetics.

Palmatier, R.W., Dant, R.P., Grewal, D., \& Evans, K.R. (2006). Factors influencing the effectiveness of relationship marketing: A meta-analysis. Journal of Marketing, 70(4), 136-153

https://doi.org/10.1509/jmkg.70.4.136

Pham, M. (1998). Representativeness, relevance, and the use of feelings in decision making. Journal of Consumer Research, 25(2), 144-159.

Pham, M. T. (2004). The logic of feeling. Journal of Consumer Psychology, 14, 360-369.

Rajava, N., Saari, T., Salminen, M., Laarni, J., \& Kallinene, K. (2006). Phasic emotional reactions to video game events: A psychophysiological investigation. Media Psychology, 8, 343-367.

Roese, N. J., \& Maniar, S. D. (1997). Perceptions of purple: Counterfactual and hindsight judgments at Northwestern Wildcats football games. Personality and Social Psychology Bulletin 23(12), 1245-1253.

Ruiz-Belda, M. A., Fernandez-Dols, J. M., Carrera, P., \& Barchard, K. (2003). Spontaneous facial expressions of happy bowlers and soccer fans. Cognition and Emotion, 17(2), 315-326.

Russell, J. A., \& Mehrabian, A. (1977). Evidence for a three-factor theory of emotions. Journal of Research in Personality: 11, 273-294.

Schwarz, N., Strack, F., Kammer, D., \& Wagner, D. (1987). Soccer, rooms, and the quality of your life: Mood effects on judgments of satisfaction with life in general and with specific domains. European Journal of Social Psychology, 17, 69-79.

Sloan, L. R. (1979). The function and impact of sports for fans: A review of theory and contemporary research. In J. H. Goldstein (Bd.), Sports, games, and play: Social and psychological viewpoints (pp. 219-262). Hillsdale, NJ: Erlbaum.

Snyder, C. R., Lassegard, M., \& Ford, C. E. (1986). Distancing after group success and failure: Basking in reflected glory and cutting off reflected failure. Journal of Personality and Social Psychology, 51, 382-388.

Tajfel, H. \& Turner, J. C. (1986). An integrative theory of intergroup conflict. In S. Worchel \& W. Austin (Eds.), Psychology of intergroup relations (pp. 2-24). Chicago: Nelson-Hall. 
Trail, G. T., Fink, J. J. \& Anderson, D. F., (2000). A theoretical model of sport spectator consumption behavior. International Journal of Sport Management, 1(3), 154-180.

Turner, J. C. (1982). Toward a cognitive redefinition of the social group. In H. Tajfel (Ed.), Social identity and intergroup behavior (pp. 15-40). Cambridge, England: Cambridge University Press.

Volz, K. G., Kessler, T., \& von Cramon, D. Y. (2009). In-group as part of the self: In-group favoritism is mediated by medial prefrontal cortex activation. Social Neuroscience, 4(3), 244-260.

Vrana, S. R., \& Lang, P. J. (1990). Fear imagery and the startle-probe reflex. Journal of Abnormal Psychology, 99(2), 189-197.

Wann, D. L., \& Branscombe, N. R. (1995). Influence of identification with a sports team on objective knowledge and subjective beliefs. International Journal of Sport Psychology, 26, 551-567.

Wann, D., \& Grieve, F. G. (2005). Sport spectator identification scale. Journal of Social Psychology, 14, 531-545.

Wann, D. L., Melnick, M. J., Russell, G. W., \& Pease, D. G. (2001). Sport fans: The psychology and social impact of spectators. New York: Routledge Press.

Westbrook, R. A., \& Oliver, R. L. (1991). The dimensionality of consumption emotion patterns and consumer satisfaction. Journal of Consumer Research, 18(June), 84-91. 